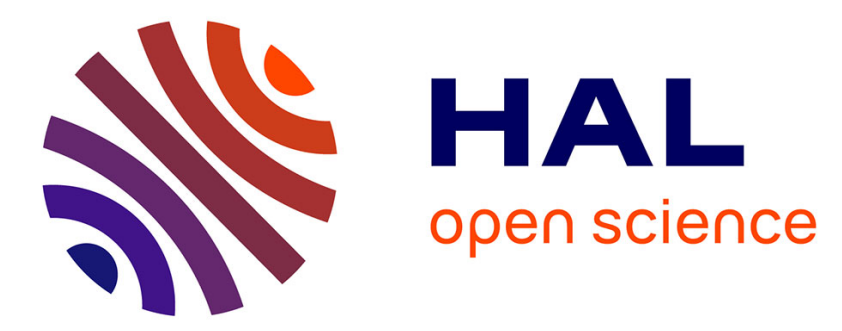

\title{
Inter-sentential anaphora and coherence relations in discourse: a perfect match
}

Francis Cornish

\section{To cite this version:}

Francis Cornish. Inter-sentential anaphora and coherence relations in discourse: a perfect match. Language Sciences, 2009, 31 (5), pp.572-592. hal-00966791

\section{HAL Id: hal-00966791 \\ https://hal-univ-tlse2.archives-ouvertes.fr/hal-00966791}

Submitted on 27 Mar 2014

HAL is a multi-disciplinary open access archive for the deposit and dissemination of scientific research documents, whether they are published or not. The documents may come from teaching and research institutions in France or abroad, or from public or private research centers.
L'archive ouverte pluridisciplinaire HAL, est destinée au dépôt et à la diffusion de documents scientifiques de niveau recherche, publiés ou non, émanant des établissements d'enseignement et de recherche français ou étrangers, des laboratoires publics ou privés. 
Inter-sentential anaphora and coherence relations in discourse: A perfect match*

(Published in Language Sciences 31 (2009), pp. 572-592)

Francis Cornish ${ }^{\mathrm{a}}$,

${ }^{a}$ Université de Toulouse-Le-Mirail

and CLLE-ERSS, CNRS UMR 5263,

Département Etudes du Monde Anglophone,

5, Allée Antonio Machado,

31058 Toulouse Cedex 09,

France

Email: cornish@univ-tlse2.fr 


\begin{abstract}
Hobbs (1979) ('Coherence and Coreference', Cognitive Science 3, 67-90) claims that the interpretation of intersentential anaphors 'falls out' as a 'by-product' of using a particular coherence relation to integrate two discourse units. The article argues that this is only partly true. Taking the reader's perspective, I suggest that there are three stages in invoking and implementing a given coherence relation to integrate two discourse units when updating a given discourse context. Interleaved with these are two distinguishable levels in the assignment of reference to the anaphor(s) in the second unit: first, through a search for evidence for the appropriateness of a given anticipated relation, the reader will provisionally assign a referent to the anaphor(s) in the second unit via the semantic structure within the relation's definition (this would correspond to Hobbs's original thesis); and second, in coming to a final decision as to the applicability of the coherence relation(s), the anaphor(s) will receive a full, expanded interpretation. This in turn will serve to actually implement the coherence relation initially assumed. In more general terms, the article aims to pinpoint the precise nature of the interactions between the invocation and implementation of given coherence relations and the functioning of anaphors in noninitial units, in processing multi-propositional texts.
\end{abstract}

Keywords: Anaphora; Coherence relations; Cohesion; Context; Discourse; Text

\title{
1. Introduction
}

As the title suggests, I am going to deal with the influence of coherence relations (CauseConsequence or Result, Circumstance, Claim-Evidence, Contrast, Elaboration, Explanation, Occasion, Parallel, etc.) on the way in which anaphora operates and is interpreted in (short) texts. Both coherence relations and anaphoric ones have as their raison d'être to facilitate the reader's or the listener's task of integrating the contents and discourse values of the incoming clauses of a text into a more global interpretative structure. Both phenomena serve to establish the continuity of meaning and reference without which a sequence of clauses and sentences would not be a text. The two discourse procedures will be shown to be in symbiosis one with the other (and so, to constitute 'a perfect match'). Thus not only does the interpretation (or 'resolution') of the anaphor(s) concerned flow naturally from this integrative effort (cf. Hobbs, 1979; Kehler, 2002; 2004), but also the nature of the in-context resolution of the anaphors in subsequent sentences or clauses will actually clinch a coherence relation whose appropriateness may only have been favored by factors associated with the interpretation of the preceding one(s).

Hobbs's general hypothesis is that once a particular coherence relation has been selected for integrating the propositions and illocutions derived from two adjacent (or nonadjacent) clauses or sentences, in the sense that it can effectively be applied satisfactorily to the relevant units associated with them, then the interpretation of any anaphoric expressions in the second such clause or sentence is ipso facto implemented: 'The solutions to many problems of reference and coreference simply 'fall out' in the course of recognizing the coherence relations' (Hobbs, 1979, p. 68). No special principles for anaphor resolution need to be invoked, Hobbs claims, over and above those needed for the establishment of a particular coherence relation integrating the contents of the two textual units.

The article aims to show that the full reference of anaphors not only 'falls out' of the selection of a given coherence relation to integrate two discourse units: in fact, it is essential for the very implementation of that relation. It further shows that the integration of discourse units in terms of coherence relations and anaphor resolution occurs in three distinguishable stages, rather than in one fell swoop, as Hobbs's characterization implies. Indeed, the true situation regarding text understanding in terms of coherence relations and anaphora will be shown to be somewhat more complex than is reflected in the account given by Hobbs (1979; 1990). I will be proposing certain modifications of his definitions and classifications of coherence relations, and will attempt to formulate the semantic structure of four further 
relations, not defined by Hobbs (Cause-Consequence, Circumstance, Claim-Evidence and Temporal Sequence/Narration), in terms of his system. Moreover, I will be putting forward a range of factors, not noted as such by Hobbs, that help create the conditions for invoking one or other particular coherence relation - or even more than one simultaneously, on occasion -, in order to integrate the content and discourse values of given discourse units.

After a short, preliminary section (section 2) distinguishing amongst the interdependent dimensions of text, context and discourse, section 3 starts by reanalyzing Hobbs's (1979) key example presented as illustration of his hypothesis. It then goes on to briefly analyze two short news articles. This makes it possible to give an initial characterization of how particular coherence relations may be invoked to integrate the discourse units isolatable from the text. The discussion includes the formal, textual as well as semantic and encyclopedic cues allowing particular coherence relations to be invoked. Section 4 then examines the theoretical basis of a number of coherence relations, mainly in terms of two relatively recent accounts: those of T. Sanders and his associates and (more centrally) of J.R. Hobbs - but references are made throughout to comparable analytic positions adopted by other linguists as well, such as N. Asher and A. Lascarides, A. Kehler, W.C. Mann and S.A. Thompson, and E. Roulet. Section 5 analyzes in detail three further English texts (news-inbrief articles) in the light of an augmented version of Hobbs's (1990) system, in order to put his hypothesis to the test. In doing so, it highlights some of the interactions between the implementation of given coherence relations and the functioning of anaphors of various kinds in understanding these texts. Section 6 concludes the discussion by sketching a processing scenario in which the facts pertaining to these interactions might be incorporated.

\section{Text, context and discourse}

As a preliminary to the discussion and analyses to come, let us first draw a three-way distinction amongst the dimensions of text, context and discourse (see Table 1 below).

Table 1. The respective roles of Text, Discourse and Context (Cornish, 2008, Table 1, p. 998,rrevised)

\begin{tabular}{|c|c|c|}
\hline Text & Discourse & Context \\
\hline $\begin{array}{l}\text { The connected sequence of verbal } \\
\text { signs and non-verbal signals in } \\
\text { terms of which discourse is co- } \\
\text { constructed by the discourse } \\
\text { partners in the act of } \\
\text { communication. }\end{array}$ & $\begin{array}{l}\text { The product of the hierarchical, } \\
\text { situated sequence of utterance, } \\
\text { indexical, propositional and } \\
\text { illocutionary acts carried out in } \\
\text { pursuit of some communicative goal, } \\
\text { and integrated within a given context. }\end{array}$ & $\begin{array}{l}\text { The context (the domain of } \\
\text { reference of a given text, the co- } \\
\text { text, the genre of speech event in } \\
\text { progress, the discourse constructed } \\
\text { upstream, the socio-cultural } \\
\text { environment assumed by the text, } \\
\text { and the specific utterance situation } \\
\text { at hand) is subject to a continuous } \\
\text { process of construction and revision } \\
\text { as the discourse unfolds. It is by } \\
\text { invoking an appropriate context } \\
\text { (which is partly determined by the } \\
\text { co-text, as well as by its genre) that } \\
\text { the addressee or reader may create } \\
\text { discourse on the basis of the } \\
\text { connected sequence of textual cues } \\
\text { that is text }\end{array}$ \\
\hline
\end{tabular}

The text is the trace of at least one utterance act (whether realized in terms of a verbal, linguistic trace, or of a non-verbal one - which may be gestural, sensori-perceptual or prosodic). Among the relevant non-verbal signals are nods of the head, winks, gaze direction, pointing gestures, raising of the eyebrows, and so on; and in the written form of language, italics, boldface, underlinings, punctuation and layout generally. Text, then, refers to the 
connected sequences of signs and signals, under their conventional meanings, produced by the speaker and (in informal spoken interactions) by the addressee - certain of which point to possible ways of grounding the discourse to be constructed within a particular context, in cognitive terms. These signals correspond to what Gumperz (1992a, p. 234) calls 'contextualization cues' (see also Auer, 1992, as well as Gumperz, 1992b).

The discourse partners exploit this trace by simultaneously invoking an appropriate context ${ }^{1}$ in order to construct discourse. The context relevant for a given act of utterance is a composite of the surrounding co-text, the domain of discourse at issue, the genre of speech event in progress, the situation of utterance, the discourse already constructed upstream and, more generally, the socio-cultural environment which the text presupposes. The various aspects of this context are in constant development: the discourse derived via the text both depends on it and at the same time changes it as this is constructed on line (cf. also Connolly, 2007; Unger, 2006). The context invoked will serve to select the relevant sense of given lexemes, will narrow this down so as to be compatible with the discourse already constructed, and will in general act to disambiguate potentially multiple possible interpretations of given textual segments (cf. Asher and Lascarides, 1996). It will also make it possible to flesh out elliptical or indeterminate references in the co-text, and to enrich allusions made in the text to real-world knowledge. Furthermore, it will help the recipient to determine the illocutionary force of each incoming clause. The genre (and sub-genre) of the text is also an important contextualizing factor (see Unger, 2006 for a cognitive-pragmatic account of genre in terms of Relevance theory). This has to do with the user's particular set of expectations based on his or her familiarity with the type of language event involved: in this article we will be exclusively drawing our attested examples from the sub-genre of news-in-brief items within the broader genre of UK or US written broadsheet journalism. Here the style and structure of the article is determined by considerations of factual objectivity, but at the same time by the need for brevity and the achievement of maximum impact via the title and initial lead sentence. These short articles are generally constructed according to the "inverted pyramid" strategy, whereby the key fact or event selected is presented first, with background or supporting information following in descending order of importance.

Discourse, on the other hand, refers to the hierarchically structured, mentally represented product of the sequence of utterance, propositional, illocutionary and indexical acts that the participants are jointly carrying out as the communication unfolds. Such sequences have as their prime objective the realization of a local and/or global communicative goal of some kind (see Parisi and Castelfranchi, 1977). Discourse, then, is both hierarchical and defeasible (a provisional, and hence revisable, construction of a situated interpretation); whereas text is essentially linear - though in the spoken medium, paralinguistic, non-verbal signals may well co-occur simultaneously with the flow of verbal signs and signals. It is the discourse constructed in terms of the text and a relevant context which is capable of being stored subsequently in long-term memory for possible retrieval at some later point. The textual trace of the communicative event, for its part, is short-lived, disappearing from shortterm memory once that discourse is constructed - or very soon thereafter (see, e.g., Jarvella, 1979).

The crucial point about this distinction is that discourse is a (re-)constructive, and so highly probabilistic matter: from the addressee's or the reader's point of view, it is in no sense a question of simply decoding the text in order to arrive at the complete message intended by the speaker/writer. 'Meaning' does not lie completely 'within' the text, it has to be constructed by the addressee or reader (and the speaker/writer!) via the text in conjunction

\footnotetext{
${ }^{1}$ See Akman and Bazzanella (eds.) (2003), Connolly (2007), Fetzer (2004) Givón (2005) and Peleg, Giora and Fein (2004) for accounts of the various types of context operating in text and discourse, as postulated by a range of different approaches to language use.
} 
with an appropriate context. In any event, the text is always incomplete and indeterminate in relation to the discourse that may be derived from it with the help of a context - including knowledge of the world, the genre of which the text at hand is an instance and the social and communicative conventions that regulate the relevant language event (cf. also Bianchi, 2004: pp. 3, 5; Widdowson 2004, p. 8; Jaszczolt 2005, p. 13). Text, context and discourse, then, are interdependent, interactive and inter-defining.

\section{Anaphora and coherence: a preliminary analysis of their interaction}

Let us begin by reanalyzing Hobbs's $(1979$, p. 78) central example (3):

\section{John can open Bill's safe. He knows the combination.}

In (1), either of the male human referents evoked in the first sentence may be retrieved in principle via the masculine singular subject pronoun he in the second. Moreover, the property of "knowing the combination [number] of the lock of a particular safe" can be plausibly applied to either of the referents at issue (to 'Bill', since the safe in question belongs to him, and to 'John', since this is what the first sentence asserts). However, it is only when the pronoun he in the second sentence is understood as applying to 'John' that the proposition it expresses can be construed as Evidence for the Claim asserted about John via the first. The first sentence may be analyzed as a 'thetic' (all-new information) utterance and the second as a topic-comment ('categorical') one, picking up as topic the more prominent referent evoked via the first ('John'). Construing he as referring back to 'Bill' in (1) would not enable the proposition so created to give further information about 'John'. Indeed, it would be singularly uninformative. Continuity of the situation evoked via the assertion of the first sentence would therefore not be assured. Strictly speaking, rather than the resolution of the pronoun he simply 'falling out' of the establishment of a coherence relation integrating the two units, as Hobbs (1979) claims, this is actually a prerequisite for the implementation of an appropriate relation; but it is clear that the two procedures work hand-in-hand.

One argument in favor of the relevance of the relation Claim-Evidence rather than a simple 'Elaboration' in the case of (1), is the fact that the connective after all may coherently be inserted between the two sentences - without altering the original interpretation in any way. Clearly, the expansion of the definite elliptical NP the combination in the second sentence will be effected anaphorically as 'the combination number of the lock on Bill's safe' as part of the implementation of the coherence relation Claim-Evidence - partly as a function of the reader's knowledge about safes.

Hobbs actually analyzes the second sentence of (1) as being in an Elaboration relation with respect to the proposition evoked via the first (in the sense that it is the same proposition that is inferred in each case, albeit expressed in terms of different words): if X can open $Y$, where $\mathrm{Y}$ is a safe, then $\mathrm{X}$ knows the combination number which enables $\mathrm{Y}$ to be opened (safes usually being secured by this means). This is clearly the case here; but this more basic relation connecting the two propositions may (and indeed, must) be strengthened by construing the first sentence as asserting a particular Claim, and interpreting the second as giving the addressee or reader grounds for believing that Claim. The presence of the modal auxiliary can in the present tense with a stative value (the host predicator being 'can open') in conjunction with the thetic value of this initial sentence as an utterance, work together to give it the status of a Claim. The anaphoric link between the subject pronoun he and the referent of the subject of the initial sentence, John (as well as the anaphoric relation connecting Bill's safe and the direct object NP the combination), contribute to giving the second sentence the status of a categorical topic-comment utterance, predicating a property of the referent 'John'. 
The tense of this second sentence is also the present, bearing a stative value via the stative Aktionsart (lexical aspect) of the predicator 'know'. Hence there is no temporal progression in this text, the situation denoted by the second sentence being identical to the one evoked by the first (cf. Dowty, 1986).

If all that was at issue in understanding text (1) were a mere paraphrase by the second sentence of the first, then this would violate a basic principle of communication: 'Do not tell your addressee what $\mathrm{s} /$ he already knows - unless there is a good reason for doing so'. This would be the case if the second sentence were construed as evidence for the claim made via the first - the speaker/writer feeling the need to persuade the addressee/reader of the plausibility of his or her claim. See text (6) below ${ }^{2}$ for an attested instance of the integration of two discourse units initially in terms of the relation Elaboration, which is then strengthened to Claim-Evidence. See Table 3 in section 4 for definitions of these two relations.

Let us take a preliminary look now at two attested texts, in order to determine just how coherence relations of various kinds may be invoked by the reader, and what role anaphors play in this.
Hamster grounds flight
An escaped hamster forced an Australian Airlines flight to make an early landing on a flight from Palma de Mallorca, Spain, to Graz after its owner admitted he had smuggled the rodent on board and could not find it. The jet was grounded for fear it might chew through a vital cable. (The Guardian Weekly 6-12.10.06, p. 2)

In text (2), the highly encapsulated title attracts the reader's attention through the incongruity of the situation evoked: however, on reading the item, it becomes apparent that the hamster in question was not directly or agentively responsible for the flight being grounded (as the title strongly implies), but played a more indirect role. Yet phrased in this way, it obviously has a greater 'news' value and its impact is enhanced. Nonetheless, the basic causal relation between the (unrestrained) hamster and the grounding of the aircraft in which it was traveling is clearly expressed via this title — which acts as a summary of and 'frame' for the essential information conveyed by the body of the piece, as well as stimulating the reader to read the item to ascertain the circumstances of this unusual event.

The first (lead) sentence is a thetic, event-reporting utterance (re-presenting in more detail as an 'all-new' state of affairs the situation outlined in the title) and does not predicate anything of a topic entity: indeed, the main-clause subject NP is indefinite and introduces a discourse-new referent which is presented as an integral part of the situation described. The subordinate clause introduced by the preposition after in lines 2-3 would be construed initially as contracting an Occasion relation (see Table 3 below, cell $1,1^{\text {st }}$ column) with the main event evoked by the initial clause: the temporal anteriority of the event it evokes is signaled via after and the past perfect tense of the verb (had smuggled). But this may be strengthened to Cause-Consequence (Result), where the losing of the hamster in the plane is construed as the immediate cause of the aircraft's forced landing - this is actually asserted in the initial clause, as well as indicated in the title.

\footnotetext{
2 Here, and in $\S 3.1$ (where I illustrate the textual and semantic cues to certain coherence relations), in particular, I refer the reader to examples yet to come, in section 5 . This is unfortunately unavoidable, since the three text examples presented early on in the article (items (1)-(3)) do not illustrate all of the textual and semantic cues or coherence relations being described here. To avoid tiresome switching back and forth in the article, therefore, the reader may wish to take on trust, for the moment, my forward references to textual illustrations of these cues and coherence relations, assessing them only when s/he reaches the analyses of these texts ((5)-(7)) in section 5 .
} 
The second sentence refers anaphorically to the aircraft via its definite subject NP the jet, and as such connects up with the more global situation evoked by the first clause of the text. This connection is also indicated by the passive verb group was grounded, which expresses an entailment of the phrase forced...to make an early landing in the initial clause. The first clause of the second sentence (The jet was grounded) would thus be in an Elaboration relation with the initial clause of the text, according to Hobbs (1990), since both entail the same proposition. However, the modifying prepositional phrase for fear it might chew through a vital cable provides the effective reason for the fact that the aircraft was forced to make an early landing. The pronoun it must refer back to 'the hamster' (and not to 'the jet'!), since hamsters, but not jets, can well 'chew through vital cables'. In this way, it is in part by referring back to the macro-topical referent 'the escaped hamster' presented as the cause of the aircraft's forced landing in the first clause, that the second sentence as a whole may be construed as providing the reason which fully explains it. So the discourse import of the second sentence contracts an Explanation relation with the result of the integration of the two clauses that make up the first.

Here now is another attested example, drawn from American news journalism. This short text differs from the ones given above in that there is no ostensible anaphor (or indeed, connective) signaling the way in which the content of the second sentence is intended to be integrated with that of the first:

\section{Car Bomb Kills 9 Near U.S. Embassy in Lima \\ A powerful car bomb exploded near the U.S. embassy in Lima on Wednesday night, $\boldsymbol{o}$ killing at least nine people and wounding dozens. President Bush plans to visit Peru this weekend. (New York Times on the Web, March 21, 2002 - 6:56 AM ET)}

In this short item, the title summarizes and highlights the essential situation described by the body of the text, giving circumstantial information (the number of dead victims, and the location of the car bomb). The first, lead sentence, again a thetic ('all-new') utterance, represents in more detail the factual content of the situation described. The content of the nonfinite, participial clause ..., $\boldsymbol{\varnothing}$ killing...dozens, since it presents further details about the situation evoked by the first, would be integrated in terms of the relation Elaboration - the zero subject of the dependent clause retrieving the main event ('the explosion of the bomb').

The second sentence is not formally connected to the first, but its content would be integrated into the context set up once it has been processed, partly in terms of certain aspects of the textual and encyclopedic knowledge presupposed (same location, Lima being the capital of Peru), and expected inferences from these. ${ }^{3}$ It is certainly in terms of the encyclopedic relations 'Lima' - 'Peru' and 'US embassy' - 'George Bush' that the propositions expressed by each of these two independent sentences are integrated: for it is in terms of a 'part-whole' relation, where the proper noun Peru acts in quasi-anaphoric fashion, that the referent 'Lima' is retrieved in virtue of the metonymic relation 'capital of a country' 'country as a whole'. If pronounced, this sentence would contain a nuclear pitch accent on the first syllable of visit (...['vizit pəru]...), and not on the second syllable of Peru (\#...[vizit pə'ru]]...). ${ }^{4}$ This indicates that Peru is thematic and not rhematic in status here.

Elaboration may be invoked minimally here in terms of the fact that in the initial

\footnotetext{
3 Schauer and Hahn (2000, p. 230) report that, in their corpus of 37 German texts taken from a wider set of reports in the field of Computer Science, 159 of the elementary discourse units $(26.1 \%$ of the total) contained neither coreference relations nor 'cue phrases'. As a result, according to Schauer and Hahn, integration of the independent successive sentences seemed to require a large amount of world knowledge, as well as inferences.

4 The crosshatch with which this phonetic realization is prefixed here signals pragmatic infelicity in the context at issue.
} 
sentence, we learn that the American embassy in Lima, capital of Peru, has (presumably) been targeted by a bomb blast; while in the second, it is stated that the then American president was to visit Peru, and so inevitably also its capital, shortly afterwards. What is held constant from the initial sentence in this 'Elaboration' by the second is the official US representation in Lima; to this, a further item of information is indicated as needing to be added: namely, the US president's planned forthcoming visit to the country. From this purely factual basis, a further, more specific discourse relationship may then be constructed.

Minimally, then, this analysis first selects the discourse relation Elaboration in order to ensure the integration at issue; but this may be enriched at a second stage, in virtue of the relevant world knowledge that a reader may have, to that of potential Consequence-(Indirect) Cause - that is, Explanation: see the definition of this relation in Table 3, col. 1, cell 3, below. Note that the possibility of such a relation here is in contradiction with the temporal constraint on the applicability of the relation Explanation imposed by Asher and Lascarides (2003, p. 160, 'Temporal Consequence of Explanation' (b)): namely that the causing eventuality should precede in time, but not follow, the caused eventuality which it 'explains' (see cell 3, col. 1, in Table 3). ${ }^{5}$

\subsection{Textual and semantic cues for coherence relations}

Let us recapitulate at this point some of the main textual and semantic cues that the reader may use in order to integrate the contents and discourse values of the sequences of clauses and sentences within a text. The coherence relations we have seen at work in the texts presented so far are as follows: Elaboration, Claim-Evidence, Occasion, Cause-Consequence (Result) and Explanation.

In the first instance, it is the predicating elements within two segments that serve as a basis for establishing the nature of the 'Expansion' or 'Resemblance' coherence relation ${ }^{6}$ in terms of which their contents and discourse values are to be integrated. In more general terms, the criterion involves determining what is predicated of what in each unit, and how these predications may be related. The predicators involved may also be related, I would claim, in terms of the following types of lexical relations: antonymy for Contrast; converse or synonymy for Parallel; and meronymy, hyponymy or again synonymy or converse for Elaboration (see text (5) in section 5, where the predicators of the two independent sentences are in a relation of synonymy) or Claim-Evidence. See Murphy (2003) for a recent critical, indepth discussion of the semantic relations holding among lexemes.

Secondly, the tense carried by the verb in the dependent unit in 'subordinating' coherence relations (see $\S 4.1$ below) such as Circumstance, Claim-Evidence, Elaboration, Occasion or Explanation may be the past perfect, signaling a shift of event time to a state of affairs preceding the one evoked by the dominant proposition: see as illustration the temporal subordinate clause in lines 2-3 of example (2) above. Such a move will indicate the nonrelevance of a possible Narration relation between the eventualities denoted by the two units, and instead the likelihood of a commentary on, or an explanation of, the 'dominant' state of

\footnotetext{
5 This dual possibility (a minimal 'Elaboration' overlain by a maximal 'Explanation') reflects the tendency of understanders to 'boost' weaker coherence relations to stronger ones, in particular those involving causality. See Ruhl (1974) on this point, as well as Sanders and Noordman (2000) on the differences in levels of integration amongst the various types of coherence relations. See also Spooren (1997, p. 153), who claims that 'as a general rule, causal relations are more specific than additive relations' [those of Elaboration or List, for example - FC]. Wolf, Gibson and Desmet (2004), in discussing the results of their self-paced, word-by-word reading time experiment, note that the critical target pronouns were read faster in the context of a cause-effect coherence relation relating two clauses, than in that of a resemblance relation. In more general terms, the sensitivity of anaphor resolution to the nature of the coherence relation most naturally invoked to integrate the contents of two discourse units has also been confirmed experimentally by Arnold (2001) and by Yang et al. (2001).

${ }^{6}$ Here, Parallel, Elaboration, Contrast and Claim-Evidence: see Table 3, $3^{\text {rd }}$ column, below for definitions of these relations.
} 
affairs just evoked - a situation which may point to the relevance of a relation such as ClaimEvidence or Elaboration. The simple present tense together with the stative Aktionsart of the main verb will favor a 'generalizing' reading of a text sentence. See as examples can open in the first sentence of (1), as well as has in $\mathrm{D}$ (iscourse) $\mathrm{U}(\text { nit })^{\circ}$ in text (6) in section 5. This is particularly the case where the unit initiates the sequence, and thus makes it likely that the utterance act realized will constitute a Claim which will shortly be supported by appropriate Evidence. The fact that the main verb of the initial clause or sentence carries the present perfect tense/aspect (e.g. has discovered in (5) below) may also serve to signal a generalization, and hence a possible Claim, or (as in (5)) a resulting situation which requires some Explanation - or at the very least, Elaboration. In more general terms, the heuristic at issue here is the temporal and aspectual relations signaled (via verb tenses or temporal adverbials of various kinds: for example, on Wednesday night and this weekend in (3) above) as holding between the propositions and illocutions expressed by each unit in the text. See Arnold (2001, p. 156) and Gennari (2004) on the discourse-pragmatic significance of tense, in particular.

The Aktionsart of each of the two predicators - whether state, activity, or event (achievement or accomplishment) - in conjunction with the aspectual, tense, mood and voice selections made for each clause, and in a wider context, the event structure of the two units involved as a whole, clearly play a role in the invocation of an appropriate coherence relation. As an illustration, see the stative predicators 'can open' and 'know' in (1) which do not change the situation evoked via each sentence; in addition, see the 'achievement' predicators 'discover' and 'find' (the latter in the passive voice) in (5) below, which also do not cause the time-line of the discourse to advance (partly because of their synonymy). See Rothstein (2004) for a recent discussion of Aktionsart and event structure, Dowty (1986), and Madden and Zwaan (2003) for a psycholinguistic perspective. A further relevant factor is the information structure (message organization) of the two textual units subject to integration i.e. whether they are thetic (see the initial sentences of each of (1) - (3) above) or categorical, topic-comment utterances (see the second sentences of (1) and (2)); and in the latter case, whether they manifest unmarked predicate focus (a topic-comment articulation), or marked argument (contrastive) focus.

Finally, one heuristic proposed by Hobbs, as also by Knott and Sanders (1998), is to see what connective (conjunction or sentence adverbial) it would be most appropriate to insert between the two units, in order to make the nature of their relation explicit: for example, then for the relations Occasion or Narrative, when, while or as for Circumstance, because for Explanation, so for Cause-Consequence (Result), and, also or too for Parallel, but for Contrast, and so on. But as Knott \& Sanders (1998, p. 142) rightly point out, there is no oneto-one relation between coherence relations and connectives, the latter often having several potential cohesive functions (cf. also Rossari, 2000). Yet they do nonetheless constitute a heuristic that is in principle useful (we used this heuristic in helping to decide on the coherence relation appropriate in the case of example (1) above). None of the factors outlined above is individually sufficient to invoke a given coherence relation; but the interaction amongst several of them simultaneously may well have the effect of favoring one or other type of relation in context - as we shall be seeing in the detailed analyses of three short texts in section 5 .

With the sole exception of the heuristic provided by certain discourse connectives, Hobbs (1990) does not exploit such formal, textual and semantic features in distinguishing between the different types of coherence relation that he puts forward. Rather, he invokes them quasi-exclusively in terms of knowledge-based criteria formalized as axioms leading to the drawing of inferences, via which the reader makes sense of texts. In Mann and Thompson's Rhetorical Structure Theory model too (Mann and Thompson, 1988), no 
systematic appeal is made to particular linguistic cues in invoking given coherence relations to integrate two discourse units (but see Mann et al. 1992, pp. 64-5 for a range of connectives recognized by RST). ${ }^{7}$ As a result, it is not always easy to determine whether one or other relation is applicable in any given instance.

\section{Some theoretical accounts of coherence relations}

Coherence relations, then, are not to be found within the co-text: they are not intrinsically textual at all, contra Schwarz (2001), who argues for the opposite position - even though they are clearly triggered via textual elements (e.g. connectives) as well as via relevant world knowledge, as we have already seen in analyzing examples (1) - (3) in section 3. Rather, they are regular cognitive 'routines' which are exploited by readers or hearers in order to enrich the texts they are processing, and in order to complete and integrate the propositions which they infer from these texts in terms of an appropriate context, assigning to each of them an appropriate illocution: so they are the 'scaffolding', as it were, that enables the reader or addressee to construct discourse on the basis of text and context. ${ }^{8}$ See also in this regard Mann and Thompson's (1986) notion of 'relational propositions' - interconnecting implicit propositions which are automatically inferred by the reader or hearer in order to link the ones extracted from the overt clauses in a text. As we have seen (in each of the texts (1) - (3) above), more than one relation may be invoked at a time in order to complete and integrate the propositions extracted - so long as these relations do not contradict one another. ${ }^{9}$ In this case, as we shall also see in $\S 4.1$ and section 5, one of the relations is normally dominant, the other(s) being merely 'supporting'.

Ted Sanders and his associates (Sanders, Spooren and Noordman, 1993) have proposed capturing coherence relations in terms of a classification schema, making it possible to reveal the system that underlies them. These relations are claimed to be based on four primitives: basic operation (the relations are either causal, or incremental ${ }^{10}$ ), polarity (positive or negative), source of coherence (semantic or pragmatic), and order of segments (unmarked or marked order). Here, I will be concerned above all with the first and third of these four primitives.

This schema makes it possible to characterize 12 classes of coherence relations (Sanders, 1997, p. 120). Sanders (1997, p. 122) defines a relation as semantic if the discourse segments concerned are connected in terms of their propositional content (the locutionary meaning of these segments). On the other hand, a relation is pragmatic if the segments are related in terms of the illocutionary value of one or of both segments: see the paraphrase test proposed as a heuristic by Sanders, given as Table 2 below. Sanders illustrates the two cases with examples 7(3) and 7(4) $((4 a, b))$ :

(4) a Theo was exhausted because he had run to the university.

b Theo was exhausted, because he was gasping for breath.

\footnotetext{
7 See also Marcu (2000) for an attempt to automatically derive RST rhetorical text structures based mainly on cue-phrases (connectives and adverbial expressions). Webber et al. (2003), for their part, make a principled distinction between 'structural connectives' (because, but, so etc.) and 'discourse adverbials' (then, otherwise, nevertheless), whose instructional meaning involves an anaphoric component. The latter work does not fall within the RST framework, however.

8 Cf. also Givón (2005), den Uyl (1983), Sanders et al. (1993), and Sanders (1997), among others.

9 Cf. also Asher and Lascarides (2003) and Hobbs (1990, p. 88). But this is contrary to what Mann and Thompson (1988, p. 249) stipulate: see the RST 'uniqueness' constraint.

10 Hobbs (1990, ch. 5) recognizes in addition a third subcategory, that of 'Ground-Figure'. See Table 3 further on in this section.
} 
Table 2: Method for establishing the source of causal ${ }^{a}$ coherence relations between pairs of successive sentences. (Sanders, 1997, pp. 126-127)

1. Isolate the two segments that are connected by a CR. Segments containing interrogatives are excluded from the paraphrase test; they are dealt with separately.

2. Strip all connectives from the sequence of segments.

3. Reconstruct the basic causal operation between the propositions $P$ and $Q$, which correspond roughly to the propositions underlying S1 and S2 (...). Paraphrase it by using one of the formulations below and consider which formulation is the best expression of the meaning of the $\mathrm{CR}$ in this context.

(i) a. the fact that $P$ causes $S$ 's claim/advice/conclusion that $Q$.

(i) b. the fact that $Q$ causes $S$ 's claim/advice/conclusion that $P$.

(ii) a. the fact that $P$ causes the fact that $Q$.

(ii) b. the fact that $Q$ causes the fact that $P$. [Note. "S" in these definitions symbolizes "the speaker'

\footnotetext{
${ }^{\mathrm{a}}$ This test only targets coherence relations of a causal type. See the first column of Table 3 listing the coherence relations under
} Hobbs's (1990) account.

A relation is pragmatic if one of the paraphrases (i) corresponds best to the $\mathrm{CR}$ as it was originally expressed in the text, and it is semantic if one of the paraphrases (ii) corresponds best to the CR expressed in the text. According to this test, the relation in (4a) would have a semantic source ("the fact that Theo had run to the University caused the fact that he was exhausted") in terms of (iib), and that in (4b) would have a pragmatic source ("the fact that Theo was gasping for breath causes S's hypothesis that he was exhausted") in virtue of (ib). Roulet (2002, p. 154) applies essentially the same test to two very similar French examples. Intuitively, the coherence relation relevant in the case of (4a) is the 'semantic' one Result (Cause-Consequence), while in (4b) it is the 'pragmatic' one Explanation (see Table 3, $1^{\text {st }}$ column, below). Of course (and this important point is not actually mentioned by Sanders), these paraphrases are only valid if the subject pronoun he in the causal subordinate clause corefers with the subject of the main clause, thereby ensuring the continuity of the situation described in the two clauses. So we see here, as we did in analyzing texts (1)-(3), the close, intimate relation holding between anaphoric retrieval, ensuring the continuity of the situation evoked via a clause or a sentence vis-à-vis the immediately preceding one, and coherence relation invoked.

Let us turn now to Hobbs. I will be referring in particular to chapter 5 of his (1990) book. For Hobbs, coherence relations are text (or rather discourse, in my terminology: see Table 1) construction strategies which the speaker or writer uses to facilitate the understander's comprehension task. The general coherence principles essentially boil down to three main types, according to Hobbs: those of 'Causality', of 'Ground-Figure', and of 'Expansion'. ${ }^{11}$ In Table 3 (see below), I have tried to classify the different sub-categories of relations recognized by Hobbs under these three headings. Bringing these definitions together in the form of a Table in this way makes it possible to compare and contrast the semantic structure of each relation directly. On occasion, I have modified an original definition (Elaboration, Explanation), have added my own (Cause-Consequence, Circumstance, ClaimEvidence and Temporal Sequence/Narration), or have altered Hobbs's classification (Explanation, shifted from 'Ground-Figure' to 'Causal'). In general, I have retained only those relations that are illustrated in the texts analyzed in sections 3 and 5 .

First of all, in the first column of the Table, the relations Occasion and CauseConsequence would, for Hobbs (1990, ch. 5), both be based on causality. The Occasion relation corresponds to the preparation by the event evoked in the first (or second) clause of

11 See also Kehler $(2002 ; 2004)$, who also draws inspiration from the three broad principles underlying discourse coherence according to Hume (see note 14), in order to model the syntactic-semantic rules underlying VP ellipsis. 
the one denoted by the clause that follows (or precedes) (see cell $1,1^{\text {st }}$ column of Table 3 ). An example given by Hobbs is: He noticed the broken connection in the control mechanism, and took it to his workshop to fix (example (7), p. 88). Kehler $(2002 ; 2004)$ places this relation in the 'Contiguity' category, corresponding to Hobbs's 'Ground-Figure' relations. This is because the end-state of the temporally prior state of affairs is the initial-state of the subsequent one. As we have seen, the event evoked by the temporal subordinate clause introduced by after in the first sentence of text (2) would initially be in an Occasion relation with regard to the main event designated by the initial clause of this sentence.

Table 3. Definitions of a subset of coherence relations, according to, and after, Hobbs (1990, Chapter 5) ${ }^{\mathrm{a}}$

\begin{tabular}{|c|c|c|}
\hline Causal Relations & Ground-Figure Relations & Expansion Relations \\
\hline $\begin{array}{l}\text { Occasion: 1) Infer a change of state } \\
\text { from the assertion of } S^{\circ} \text {, whose } \\
\text { final state can be inferred from } S^{1} \text {. } \\
\text { 2) Infer a change of state from the } \\
\text { assertion of } S^{1} \text {, whose initial state } \\
\text { can be inferred from } S^{\circ} \text {. (Hobbs, } \\
\text { 1990, p. 87) }\end{array}$ & $\begin{array}{l}\text { Ground-Figure: Infer from } \mathrm{S}^{\circ} \text { a } \\
\text { description of a system of entities } \\
\text { and relations, and infer from } \mathrm{S}^{1} \text { that } \\
\text { a certain entity is placed or moves } \\
\text { against that system as a } \\
\text { background. (Hobbs, 1990, p. 91) }\end{array}$ & $\begin{array}{l}\text { Parallel: Infer } p\left(a_{1}, a_{2}, \ldots\right) \text { from the } \\
\text { assertion of } \mathrm{S}^{\circ} \text { and } p\left(b_{1}, b_{2}, \ldots\right) \text { from } \\
\text { the assertion of } \mathrm{S}^{1} \text {, where } a_{i} \text { and } b_{i} \\
\text { are similar, for all } i \text {. (Hobbs, 1990, } \\
\text { p. 93) }\end{array}$ \\
\hline $\begin{array}{l}\text { Cause-Consequence ["Result"]: a } \\
\text { special case of the Occasion } \\
\text { relation (its "strong" version). Infer } \\
\text { that the state or event asserted via } \\
\mathrm{S}^{\circ} \text { causes or could cause the state or } \\
\text { event asserted via S }{ }^{1} \text { (FC: } \\
\text { definition based on Hobbs's } \\
\text { definition of Explanation - see } \\
\text { cell 3, this column). }\end{array}$ & $\begin{array}{l}\text { Circumstance: a proposition } P^{0} \\
\text { expressing a state, process or event } \\
\text { in } \mathrm{S}^{0} \text { will be construed as providing } \\
\text { the temporal, spatial or cognitive } \\
\text { framework within which the event } \\
\text { denoted by } \mathrm{S}^{1} \text { is to be situated. The } \\
\text { main event (expressed by } \mathrm{S}^{1} \text { ) must } \\
\text { either be wholly included in the } \\
\text { circumstantial one }\left(\mathrm{S}^{\circ}\right) \text { or overlap } \\
\text { with it (FC) (see Mann \& } \\
\text { Thompson, } 1988, \text { p. } 272)\end{array}$ & $\begin{array}{l}\text { Elaboration: Infer the same } \\
\text { proposition } P \text { from the assertions of } \\
\mathrm{S}^{\circ} \text { and of } \mathrm{S}^{1} \text {. This is in fact the } \\
\text { relation Parallel when the similar } \\
\text { entities } a_{i} \text { and } b_{i} \text { are identical, for all } \\
i \text { (Hobbs, 1990, p. 95). In addition, } \\
\mathrm{S}^{1} \text { must add further details to the } \\
\text { common proposition inferable from } \\
\text { each assertion, and } \mathrm{e}^{1} \subseteq \mathrm{e}^{\circ}(\mathrm{FC}) \text {. }\end{array}$ \\
\hline \multirow[t]{2}{*}{$\begin{array}{l}\text { Explanation: Infer that the state or } \\
\text { event asserted via } \mathrm{S}^{1} \text { causes or } \\
\text { could cause the state or event } \\
\text { asserted via } \mathrm{S}^{\circ} \text { (Hobbs, 1990, p. } \\
\text { 91). In addition, } \mathrm{e}^{1} \succ \mathrm{e}^{\circ} \text { (the main } \\
\text { event evoked by } \mathrm{S}^{1} \text { precedes the } \\
\text { one designated by } \mathrm{S}^{\circ} \text { ) (Asher \& } \\
\text { Lascarides, 2003: 160). The } \\
\text { speaker/writer intends the } \\
\text { hearer/reader to understand the } \\
\text { causal relation between the two } \\
\text { eventualities (FC). }\end{array}$} & & $\begin{array}{l}\text { Contrast: 1) Infer } p(a) \text { from the } \\
\text { assertion of } \mathrm{S}^{\circ} \text { and } \neg p(b) \text { from the } \\
\text { assertion of } \mathrm{S}^{1} \text {, where } a \text { and } b \text { are } \\
\text { similar. 2) Infer } p(a) \text { from the } \\
\text { assertion of } \mathrm{S}^{\circ} \text { and } p(b) \text { from the } \\
\text { assertion of } \mathrm{S}^{1} \text {, where there is some } \\
\text { property } q \text { such that } q(a) \text { and } \neg \\
q(b) \text {. (Hobbs, } 1990, \text { p. 99) }\end{array}$ \\
\hline & & $\begin{array}{l}\text { Claim-Evidence: } 1 \text { ) Infer } P \text { from the } \\
\text { assertion of } \mathrm{S}^{\circ} \text { and of } \mathrm{S}^{1} \text {, where } \mathrm{S}^{1} \\
\text { adds further details to } P \text { and } \mathrm{e}^{1} \subseteq \mathrm{e}^{\circ} \\
\text { (= the Elaboration relation) and } 2 \text { ) } \\
\text { Interpret } \mathrm{S}^{1} \text { as rendering more } \\
\text { convincing the speaker's hypothesis } \\
\text { corresponding to the assertion of } \mathrm{S}^{\circ} \\
\text { (FC) }\end{array}$ \\
\hline
\end{tabular}

${ }^{\mathrm{a}}$ The symbols ' $\mathrm{S}^{0}$, ' $\mathrm{S}$ ', etc. indicate "initial sentential unit", "second sentential unit", etc. within a given text. The logical and other formulae within each cell are glossed as and when they occur.

I have formulated the relation Cause-Consequence (Result in Asher and Lascarides', 2003 as well as Kehler's, 2004 frameworks) in terms of the definition Hobbs provides for the relation Explanation - where the Cause and its Effect are reversed: see cells 2 and 3 of the first column of Table 3, respectively. But Explanation presupposes that the speaker/writer 
intends the causing eventuality to 'explain' the caused one for the addressee/reader. It is not simply a question of an 'objective' (semantic) relation between two eventualities - as in Sanders' (1997) example (4a) above. I have added to the definition Asher and Lascarides' (2003, p. 160) temporal constraint on Explanation, to the effect that the causing event normally precedes the caused event. See text (2) above for an attested illustration. As Kehler (2004) notes, causal relations involve as arguments the propositions expressed by the sentences or clauses connected.

In the second column, the 'Ground-Figure Relations' (of which Hobbs cites only the relation Explanation - which I have placed more appropriately under the heading 'Causal Relations' in Table 3 - in addition to this canonical relation) are said to connect a discourse segment to the addressee's (activated) store of prior knowledge. A typical instance of a 'Ground-Figure' relation would be that of Circumstance. This is defined by Mann and Thompson (1988, p. 272) as the satellite's 'set[ting] a framework in the subject matter within which $\mathrm{R}$ [the reader] is intended to interpret the situation presented in N [the nucleus]'. See the second column of Table 3 ( $2^{\text {nd }}$ cell) for my definition à la Hobbs, inspired in part by that of Mann and Thompson. An actual example of this relation occurs in the temporal subordinate clause in text (6) below. I have added a definition of Temporal Sequence/Narration under this heading, since this relation involves the contiguity of two events, one of which follows the other in time - the second being in a sense determined by the occurrence of the first (this is the sequential relation). It is likewise a very basic relation, as are the (textual) 'Ground-Figure' relations as a whole. See Reinhart (1984, p. 785) for arguments that it is not in fact the temporal sequence of events in the represented world which determines whether we are dealing with Narration, but "properties of the [textual] presentation". To the extent that Reinhart's arguments are valid, this is added evidence that Narration is a textual rather than content-based (semantic) relation.

Finally, the 'Expansion Relations' (see the third column of Table 3: those of Parallel, Elaboration and Contrast - to which I have added that of Claim-Evidence) would be instantiations of the general principle of 'Similarity'. ${ }^{2}$ Kehler $(2002 ; 2004)$ uses Hume's original term 'Resemblance' for this category of coherence relations. For Hobbs, the 'Expansion Relations' are relations that extend the discourse in situ, rather than carrying it forward or developing its background. They all involve inferential relations between the segments of the co-text, and function to facilitate the understander's inferential processes. For Parallel, see texts (6) and (7) below, and for Contrast (which subsumes the Parallel relation), text (7).

As far as Hobbs's definition of the relation Elaboration is concerned (see the $2^{\text {nd }}$ cell of the third column in Table 3), I have appended the condition that $\mathrm{S}^{1}$, the elaborating proposition, should add information to the common proposition inferred from each clause since otherwise, the definition would amount to nothing more than a simple 'Paraphrase' relation: see Hobbs's (1979) example given as (1) above, under his 'Elaboration' analysis. This specification is actually built into Hobbs's (1979, p. 73$)$ earlier definition of Elaboration : '...(but $\mathrm{S}^{1}$ contains a property of one of the elements of $\mathrm{P}$ that is not in $\mathrm{S}^{\circ}$ )'. However, in his later work (Hobbs, 1990, p. 95), it is omitted, since Hobbs (p. 96) also intends pure repetitions to fall under this relation. But a 'repetition' is intuitively surely something rather less than an 'elaboration'. Furthermore the main event (symbolized as $\mathrm{e}^{1}$ ) evoked via $\mathrm{S}^{1}$, the elaborating unit, should be construable as forming a proper part of that denoted by $\mathrm{S}^{\circ}\left(\mathrm{e}^{\circ}\right)$, the elaborated one. $^{13}$

\footnotetext{
12 See the three principles put forward by the philosopher David Hume in section III of his Inquiry Concerning Human Understanding: respectively, Cause or Effect, Contiguity in Time or Place, and Resemblance.

13 Cf. Asher and Lascarides (2003); Fabricius-Hansen and Behrens (2001).
} 
Alternatively, as in the case of the second sentence in (3), this event may simply be locatable in the temporal or spatial frame of reference that $\mathrm{S}^{\circ}$ will have set up. This is not an instance of a 'Ground-Figure' relation here, however, since we may suppose that the initial sentence of (3) was not intended to provide the background for the assertion of the (future) event evoked via the second. The former introduces the main event in this text, evoking a situation in relation to which the second merely adds a piece of information.

On this basis, it would seem that the definitions of coherence relations should not be understood in absolute, 'categorical' terms (cf. Fabricius-Hansen and Behrens', 2001, p. 2 comment in relation to Elaboration). Rather, they are prototypes, whereby given relations between propositions or entity-denoting arguments inferable from texts in conjunction with given contexts may approximate the 'core' characterization which they represent to a greater or lesser degree. In the case of the second sentence in example (3), for instance, it is clear that the proposition it expresses cannot, strictly speaking, be integrated with the one evoked via the first in terms of the definition of Elaboration as formulated in Table 3 (the main event it evokes is not 'a proper part' of the one denoted by the initial sentence). However, as we have seen, it 'elaborates' the state of affairs introduced via the latter in a more general sense - in terms of the different forms of official representation of the country concerned (the US) in Peru. The Elaboration by the second sentence in (5) below (see section 5), however, is a more central instance of this relation - the event it evokes being the same as the one introduced by the first sentence. Although he did not use the term, the conception of coherence relation definitions as 'prototypes' was already recognized by Hobbs:

For expository reasons, I have defined the relations as though they were an all or none matter. But it should be kept in mind that ... a particular coherence relation holds between two sentential units to a greater or lesser degree, depending ultimately on the salience of the axioms used to establish the relation. (Hobbs, 1979, p. 73)

As Kehler (2004) points out, the 'Expansion' or 'Resemblance' relations all involve a relation between entity-denoting arguments, and not (directly) whole propositions, as in the case of Cause-Effect relations or Ground-Figure/Contiguity ones: see the semantic structures of each of the relations given in the third column of Table 3.

\subsection{Dominance relations between discourse units paired in terms of a coherence relation}

These relations may be divided into two macro-categories which are orthogonal with respect to the three categories recognized as establishing the various types of coherence relation (Hobbs, 1990, p. 104): namely, coordinating relations and subordinating relations. ${ }^{14}$ Amongst the first type, according to Hobbs, may be found the relations Parallel and Elaboration; amongst the second, Ground-Figure, Explanation and Contrast. The criterion used by Hobbs to classify the relations in one or other of these categories is that corresponding to the nature of what is asserted in the two sentences at issue. For the coordinating relations, there is a common proposition that may be inferred both from $\mathrm{S}^{\circ}$ and from $\mathrm{S}^{1}$; in this case, when the propositions inferred from both sentences are fused, it is this 'superordinate' proposition that will be asserted. On the other hand, in the case of the subordinating relations, one of the two propositions ${ }^{15}$ will be dominant; in such a case, it is the one expressing the dominant proposition that will be asserted, once the two propositions

\footnotetext{
14 See also Mann and Thompson (1988) for the RST 'nucleus-nucleus' and 'nucleus-satellite' relations, respectively.

15

Hobbs says 'sentences', but I think it is important to keep the semantic and syntactic levels of analysis separate here.
} 
expressed are integrated. ${ }^{16}$ According to this definition, the relation Contrast will be 'subordinating', since, intuitively, it is the proposition expressed via $\mathrm{S}^{1}$ that is dominant; yet in Table 3, it is clear that the semantic structure of this relation is very close to that of the relation Parallel, which is a coordinating relation.

By contrast, the relation Elaboration is classified as belonging to the coordinating category, since it involves the inference of a common proposition on the basis of each of the two clauses or sentences involved; however, intuitively again, the 'elaborating' proposition is dependent vis-à-vis the 'elaborated' proposition. The extended definition given in cell 2 of the third column of Table 3 would strongly support this categorization. In fact, this is how this relation is characterized by Asher and Lascarides (2003, p. 8). I would resolve this paradox by suggesting that we distinguish between two levels of analysis here (cf. also Sanders, 1997): on the one hand, the semantic level, and on the other, the pragmatic, illocutionary level - on which I believe Hobbs relies in talking of dominant or dominated propositions; this is the level of the speaker's moves, the domain of discourse interaction. This is also how Roulet (2002, p. 148) conceives of the situation, in distinguishing amongst three types of relation between units in a discourse: semantic, textual and 'praxeological' (action structure).

In this respect, in the case of the relation Contrast, the proposition inferred from $\mathrm{S}^{1}$ would be semantically equally dominant in relation to that inferred from $\mathrm{S}^{\circ}$, but dominant at the level of illocutionary acts on the pragmatic plane. And in the case of the relation Elaboration, the proposition inferred from $\mathrm{S}^{\circ}$ would be semantically on an equal footing with the one inferred from $\mathrm{S}^{1}$ (since Elaboration is underlain by the structure corresponding to the relation Parallel) - but would be dominant in relation to the latter at the pragmatic level. Nonetheless, each of the coherence relations retained here does have a basic semantic, textual or pragmatic character: Occasion, Cause-Consequence (Result), Parallel, Elaboration and Contrast would be fundamentally 'semantic' relations; Ground-Figure, Circumstance and Narration, 'textual', and Explanation and Claim-Evidence, 'pragmatic'.

The basic units isolated in terms of which the various coherence relations are to be set up will be symbolized in the texts analyzed in the next section, not as ' $\mathrm{S}$ ', ' $\mathrm{S}$ ' ' etc., as Hobbs (1990) does, but as 'DU', 'DU', etc. (where 'DU' stands for 'Discourse Unit'). I adopt this symbol here since not all of the relevant units are full 'sentences' in syntactic terms - rather, they are minimal predications. Thus in terms of the distinction amongst text, context and discourse drawn in Table 1, these are discourse and not text units. I have retained Hobbs's symbols in the definitions in Table 3, however, since these are mainly quotations from his (1990) work. See section 5 for further details of the division of a text into units.

\section{Application to three short news articles}

Let us consider now to what extent the analytic approach developed up to this point might enable us to characterize the way in which three short English texts consisting of between two and four independent sentences, would be understood. The latter are for the most part unlinked by connectives, and the non-initial sentences or clauses contain anaphors of various kinds. How does the reader understand each successive sentence in the light of his/her interpretation of the previous one(s) (as well as of the title, where there is one)?

In the following analyzed texts, I have isolated clauses, whether finite or non-finite, coordinate or subordinate, as well as nominalized predications, as expressing the basic units of discourse. Restrictive relative clauses as well as complement clauses (whether subject or non-subject) are not recognized as corresponding to distinct discourse units — cf. also Mann

16 In any case, at this level, the propositions extracted from each of the two sentences at issue here are not really separable as such. 
and Thompson's (1988, p. 248) procedural decision, based on the fact that restrictive relatives and complement clauses performing nuclear grammatical functions are integral parts of their host clauses, rather than constituting relatively independent units. Roulet (2002, p. 144) gives evidence for the correctness of this position in suggesting that restrictive relatives and complement clauses do not correspond praxeologically to distinct 'discourse acts': indeed, they are not capable in principle of operating in some way on the discourse model currently being developed.

In more general terms, there are in fact other types of relevant unit than the one assumed by both Hobbs and Mann and Thompson as being the basic discourse unit, i.e. that expressed by the clause: for example, the one corresponding to the content of nominalized predications, or even to that of PPs or NPs, according to Roulet (2002, p. 145), so long as they correspond praxeologically to minimal discourse acts. Then there are units of higher rank, formed as a result of the integration of two or more lower-ranked units: see Figures 1 and 2 below for visual displays of concrete examples of this, relating to two of the texts analyzed in this section. As already noted, the relevant units in the case of the 'Causal' and 'Ground-Figure' relations are minimal predications; while in the case of the 'Expansion' relations, they are entity-denoting arguments.

In the texts presented in this section, I annotate each minimal unit isolated in terms of its event structure (using the subscripts 'EV' for 'event' and 'ST' for 'state', as in Smith's, 2003 approach), since this plays a role in the invocation of a given coherence relation to integrate the content of two units, as we have seen. As before, anaphoric expressions, including zero anaphors, are highlighted in boldface.

Let us begin with a simple, two-sentence text:
19th-century submarine found
$\mathrm{DU}_{\mathrm{EV}}^{\circ}$ A British explorer, Colonel John Blashford-Snell, has discovered an abandoned 19th-century submarine that may have been the inspiration for Captain Nemo's vessel Nautilus in Jules Verne's 20000 Leagues Under the Sea. $\mathrm{DU}^{1}{ }_{\mathrm{EV}}$ The cast-iron submarine, $\mathrm{DU}_{\mathrm{EV}}^{2} \boldsymbol{o}$ built in 1864, was found half submerged off the coast of Panama. (The Guardian Weekly, June 10-16, 2005, p. 2)

The title of this text reflects the content and structure of the unit $\mathrm{DU}^{1}$ in that it is an elliptical passive construction, the object discovered being the key element highlighted. As in texts (2) and (3) above, this creates a frame of reference into which the more detailed information presented in the body of the text may be integrated: also like these two examples, the entire text here is in fact an elaboration of the highly condensed title. Text (5) consists of three basic units, one of which $\left(\mathrm{DU}^{2}\right)$ is marked as grammatically dependent on an independent clause, $\mathrm{DU}^{1}$, inasmuch as it is a (reduced) non-restrictive relative clause in apposition within it. It is semantically and discoursally dependent on it as well, the zero subject of built being syntactically constrained to corefer with the subject of the main clause, $\mathrm{DU}^{1}$.

The composite unit $\left[\mathrm{DU}^{1}+\mathrm{DU}^{2}\right]$ will be integrated with the central, presentational unit $\mathrm{DU}^{\circ}$ in terms of this same relation, for the following reasons: $\mathrm{DU}^{\circ}$ corresponds to an active sentence, whose tense-aspect is the present perfect, emphasizing the relevance of the result of the past event designated at the time of utterance. Its subject NP refers to the agent of the action, the individual who discovered the $19^{\text {th }}$ Century submarine. The verbal predicate's Aktionsart is technically that of 'achievement' (an event which terminates immediately or very soon after it begins); and the key information conveyed by this clause, namely the existence of the $19^{\text {th }}$ Century submarine, is expressed via an indefinite NP in postverbal object 
position. The referent of this NP is not yet a 'topic' entity, since it constitutes focused information. The first sentence, then, is a thetic utterance, serving to present the discovery of the $19^{\text {th }}$ Century submarine. As such, it anticipates some sort of explanation, or at the very least, elaboration (which is effectively the case here).

As predicted by Hobbs's (1990) definition, ${ }^{17} \mathrm{DU}^{\circ}$ and $\mathrm{DU}^{1}$ assert the same basic proposition, namely "that an abandoned $19^{\text {th }}$ Century submarine has been discovered", to which $\left[\mathrm{DU}^{1}+\mathrm{DU}^{2}\right]$ adds relevant circumstantial details: where it was found, in what state, and when it was built (the Elaboration relation). Indeed, the main verb of $\mathrm{DU}^{1}$ (find) is a synonym of the one used in $\mathrm{DU}^{\circ}$ (discover), with the same Aktionsart; and the understood agent is necessarily Col. John Blashford-Snell, the agent of the action evoked by DU ${ }^{\circ}$. All this is consistent with the invocation of the relation Elaboration. Although $\mathrm{DU}^{1}$ is a passive sentence, while $\mathrm{DU}^{\circ}$ is an active one, the integration of the two units is coherent as well as cohesive: for while syntactically the two clauses are not parallel, semantically they clearly are. The reason behind the choice of the passive voice in both $\mathrm{DU}^{1}$ and $\mathrm{DU}^{2}$ is the need to thematize the existential referent introduced postverbally in $\mathrm{DU}^{\circ}$, enabling it to be expressed in subject position (and thus empathized with - see also the title in this respect, which has identical lexical and syntactic form). See Cornelis (2003) on the perspectivizing function of passives in journalism).

The definite passive subject NP in $\mathrm{DU}^{1}$, the cast-iron submarine, serves via anaphoric coreference to select the unit which the essential content of $\left[\mathrm{DU}^{1}+\mathrm{DU}^{2}\right]$ can elaborate by picking up in topic position (the subject of a passive sentence) the focused entity introduced by $\mathrm{DU}^{\circ}$. It also serves to establish the identity of the referent required in the variable $b_{2}$ slot in the second part of the semantics of the Elaboration relation, as specified in Hobbs's (1990) definition. The agent is the same via zero realization and via the fact that the main verb of the clause (find) is synonymous with the one in $\mathrm{DU}^{\circ}$ (discover).

Now let us analyze text (6):

(6) $\mathrm{DU}_{\mathrm{ST}}^{\circ} \mathrm{Mr}$. Oliver Tambo has few admirers in the Conservative Party. $\mathrm{DU}^{1} \mathrm{EV}$ When the president of the African National Congress Party appears today at the House of Commons, $\mathrm{DU}^{2}{ }_{\mathrm{ST}}$ those present will feel obliged to give him a rough ride. (...) The Guardian, $29^{\text {th }}$ October 1985 , p. 19

In (6), the initial unit $\mathrm{DU}^{\circ}$ (a thetic utterance) evokes a generalization, and hence potentially a Claim, which as such induces a strong expectation in the reader that some kind of evidence will be provided very shortly to support it. Indeed, the tense of the lexical verb have is the simple present, and its Aktionsart is that of 'state'. $\mathrm{DU}^{1}$ is a temporal subordinate clause whose function is to provide a temporal frame of reference for the assertion via $\mathrm{DU}^{2}$ of the reaction predicted to occur at that point in time.

The main problem to be solved by the understander of $\mathrm{DU}^{1}$ is this: is the definite subject NP the president of the African National Congress Party introducing a new referent into the discourse constructed up to this point, or is it coreferential with the proper name subject in $\mathrm{DU}^{\circ}$ ? After all, as a referentially autonomous NP, it is perfectly capable of performing the former function. Now, over and above the reader's possible world knowledge that Oliver Tambo was at the time president of the ANC party, the parallel (subject) function of the two NPs here is a signal that the two expressions are indeed coreferential. See Crawley et al. (1990) for experimental evidence in this regard, as well as the situation obtaining in example (1) above. Hobbs (1979, p. 80), whose example this is, also invokes this heuristic. However,

\footnotetext{
17 See the second cell of the third column in Table 3, referring to the semantics of the Parallel relation in cell 1 of that column.
} 
in my view, it is in virtue of the fact that the subject habitually codes the topic function that it has the heuristic force that is ascribed to it. Another motivating factor here is the fact that, with this coreferential connection, $\mathrm{DU}^{1}$ may be linked, not only to $\mathrm{DU}^{2}$ (via subordination), but to $\mathrm{DU}^{\circ}$ as well.

The discourse act corresponding to the main clause $\mathrm{DU}^{2}$ is integrated within the framing temporal context put in place via $\mathrm{DU}^{1}$ (construed as Circumstance for it: note the presence of the temporal connective when) through the strong expectation it sets up that the state of affairs expressed by the following main clause overlaps temporally with its time frame (see my definition of Circumstance in cell 2, col. 2 of Table 3). It is also linked via the elliptical demonstrative phrase those present (initially understood as 'the Members of Parliament present at the House of Commons on the day of utterance when the ANC party's president [OT] appears there'), which connects anaphorically with part of it. The unified, integrated unit corresponding to $\left[\mathrm{DU}^{1}+\mathrm{DU}^{2}\right]$ is then connected to $\mathrm{DU}^{\circ}$ in terms of the relation Evidence for the Claim corresponding to the latter (see below for justification). Given this Claim-Evidence relation unifying $\left[\mathrm{DU}^{1}+\mathrm{DU}^{2}\right]$ with $\mathrm{DU}^{\circ}$, the reference of the phrase those present would then be construed, not simply as 'those MPs present at the House of Commons' at the time indicated, but more restrictedly as 'those MPs belonging to the British Conservative Party present at the House of Commons at the time at issue'. Without this restriction, the integrated proposition $\left[\mathrm{DU}^{1}+\mathrm{DU}^{2}\right]$ would not be able to provide 'Evidence' for the Claim asserted via $\mathrm{DU}^{\circ}$.

This is a clear indication, then, of how anaphora enables a particular coherence relation to be invoked and implemented in context. The same proposition "Oliver Tambo has few supporters in the British Conservative Party" is both asserted via DU ${ }^{\circ}$ (the Claim) and inferred from $\mathrm{DU}^{2}$, so this part of the structure of the Claim-Evidence relation is reflected in the units purporting to be integrated in this way (see cell 4 of the third column in Table 3 ). And the Parallel structure "Most British Conservatives $\left(a_{1}\right)$ are highly critical of Oliver Tambo $\left(a_{2}\right)$ " in DU', and "those CP MPs in the House of Commons $\left(b_{1}\right)$ will give Oliver Tambo $\left(b_{2}\right)^{18}$ a hard time when he speaks there on $29^{\text {th }}$ October $1985^{\text {" }}$ in $\left[\mathrm{DU}^{1}+\mathrm{DU}^{2}\right]$ corresponds precisely to the structure given for the Elaboration relation, which underlies Claim-Evidence. The composite discourse act corresponding to $\left[\mathrm{DU}^{1}+\mathrm{DU}^{2}\right]$ is an instantiation of the assertion in $\mathrm{DU}^{\circ}$, in that it provides a specific manifestation of the hostile attitude claimed to prevail. 'Oliver Tambo' is the same individual instantiating the parallel $a_{2}$ and $b_{2}$ variables in each part of the structure; and 'the CP MPs present in the British House of Commons when OT speaks there' $\left(b_{1}\right)$ are a representative subset of 'most members of the CP' $\left(a_{1}\right)$. Moreover, 'giving someone a rough ride' in $\mathrm{DU}^{2}$ is clearly a manifestation of the generalization to the effect that 'the person in question has few admirers among people of the category involved' in $\mathrm{DU}^{\circ}$. So $\left[\mathrm{DU}^{1}+\mathrm{DU}^{2}\right]$ elaborates $\mathrm{DU}^{\circ}$, and at the same time provides evidence for its validity as a Claim. As in the case of text (1), one of the connectives after all or indeed could coherently be inserted here between $\mathrm{DU}^{\circ}$ and $\left[\mathrm{DU}^{1}+\mathrm{DU}^{2}\right]$ to make this relation explicit.

If it is true, as I am arguing, that more than one coherence relation is possible simultaneously in integrating two discourse units, then it is the semantically 'stronger' relation which will take priority over the 'weaker' one. Evidence is semantically stronger (more specific) than Elaboration, for example, since it contains the same basic structure as the latter relation (see Table 3); but for Evidence to be applicable, the second of the two units must be interpretable as rendering the assertion of the first more convincing for the addressee or reader. So while Elaboration is a simple 'semantic' relation, Evidence is a 'pragmatic' one. Both relations are compatible, since the second part of the definitional structure of each is

18 Re-instantiated via the retrieval of this referent by means of the object pronoun him in DU². 
dependent with respect to the first. In general, a fundamentally 'pragmatic' relation will always take precedence over a basically 'semantic' or 'textual' one, where more than one relation is applicable in any given instance: see the discussion of coordinating vs. subordinating relations in $\S 4.1$ above.

Figure 1 below provides a tree representation of the discourse structure of text (6), a representation which adapts the type proposed by Hobbs (1990). See also Webber et al. (2003) for a similar type of tree representation of discourse structure. I have introduced a device (the use of bold typeface) to represent the dominant minimal discourse unit involved in a given coherence relation, under the pragmatic conception of subordinating coherence relations, as outlined at the end of the previous section -inspired by Sanders' (1997) distinction between relations whose source is semantic and those where it is pragmatic.

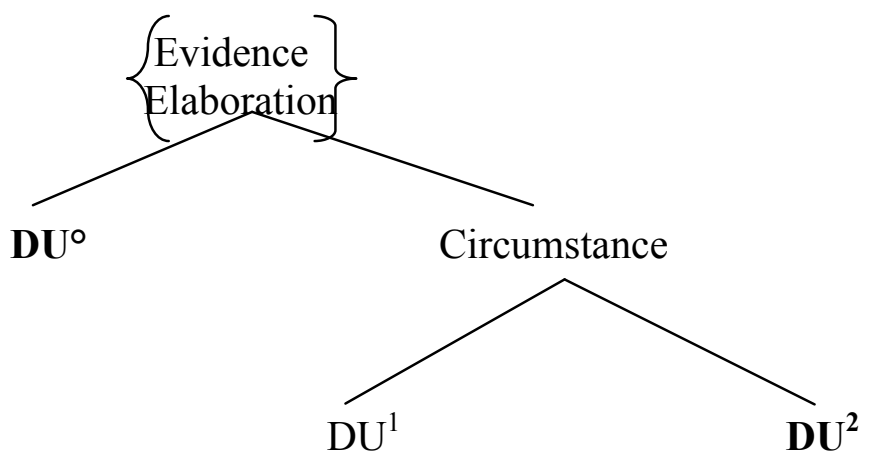

Figure 1: Schematic representation of the discourse structure of example (6), after Hobbs (1990: Ch. 5)

Note. The occurrences of the symbol $\mathrm{DU}^{\mathrm{n}}$ in Figure 1 and those below should be understood as representing the corresponding discourse acts. The symbols in bold characters at the end of the branches in this and subsequent Figures correspond to the constituent (potentially unified) discourse acts which are dominant at the pragmatic level, in relation to the one attached as sister usually to their right, which modulates them in some way. Where two distinct coherence relations apply simultaneously to integrate the contents of two units, they are displayed in the relevant Figures (1-3) according to the order of dominance (the name of the dominating relation occurs above that of the less dominant one). These are my additions to Hobbs's original tree representation format.

The representation should be read in the following way: proceed 'bottom up', from the lower nodes to the higher, first moving from left to right (the 'textual' reading process), then from right to left (i.e. upwards: the 'discourse' integration process) as a function of dominating nodes. The structure of the discourse at issue will then emerge from the successive integrations of the units involved.

However, this integration does not always proceed 'vertically', from a minimal unit towards an already-processed unit to its immediate left, on the textual level: for if a unit to the right of the one which has just been processed is accompanied by a unit marked as grammatically dependent on it (a subordinate clause, or a clause in apposition for example), then this integration must necessarily take place first. It is only then that this composite unit will be integrated with the result of the integration upstream (see for example $\mathrm{DU}^{1}$ in relation to $\mathrm{DU}^{2}$ and $\mathrm{DU}^{\circ}$ in texts (5) and (6)).

But this may also be the case when the units to the right of a given unit are dependent on it discourse-pragmatically, even though they may be expressed by independent sentences. See Fig. 2 representing text (7) below, where $\mathrm{DU}^{3}$ is extended, not only by the appositive relative clause realizing $\mathrm{DU}^{4}$ and the conjunct expressing $\mathrm{DU}^{5}$, but also by the independent sentence corresponding to $\mathrm{DU}^{6}$. A still further exception is where an adjacent unit effects a 'return pop' over intervening units to attach to a previously processed unit. Here, it is the anaphor (in conjunction with its entire host clause) which enables this to occur. See as an illustration The bursaries at the beginning of $\mathrm{DU}^{3}$ in $(7)$ below, which attaches $\left[\left[\mathrm{DU}^{3}+\mathrm{DU}^{4}\right]\right.$ 
$+\mathrm{DU}^{5}$ ] via anaphoric connection to $\mathrm{DU}^{\circ}$ - the thematic, anchoring unit for the entire text instead of to the immediately preceding unit, $\left[\mathrm{DU}^{1}+\mathrm{DU}^{2}\right]$. It can also happen that a later integration will make it necessary to revise an earlier understanding - especially if two alternative construals of that or those unit(s) were possible at that stage.

Hobbs's (1990) tree representations are merely an informal device for showing the discourse structure of texts. A number of them contain crossing as well as ternary branches, which, as in the case of purely syntactic trees, should be avoided (the trees presented in Figures 1 and 2 are only binary-branching). Moreover, Hobbs does not use the symbols that demarcate the basic discourse units in his analysis as leaf nodes.

Finally, here is a more elaborate text, consisting of 4 sentences (with 7 discourse units):

\section{Bursaries for volunteers \\ $\mathrm{DU}_{\mathrm{EV}}^{\circ}$ Imperial College London will offer annual $£ 1,500$ bursaries to 20 student volunteers supporting pupils in local primary and secondary schools. \\ $\mathrm{DU}_{\mathrm{EV}}^{1}$ The students will help teach subjects such as science, maths and information technology, $\mathrm{DU}_{\mathrm{EV}}^{2} \boldsymbol{\varnothing}$ hopefully sparking an interest that leads to further study and provides pupils with a positive image of higher education. \\ $\mathrm{DU}_{\mathrm{ST}}^{3}$ The bursaries, $\mathrm{DU}_{\mathrm{ST}}^{4}$ which are provided by financial service provider Citigroup, are available for the coming academic year $\mathrm{DU}^{5}{ }_{\mathrm{ST}}$ and $\boldsymbol{\theta}$ will be aimed at those from less well-off backgrounds. $\mathrm{DU}_{\mathrm{ST}}^{6}$ Students already involved in the scheme will not be eligible for the bursaries. (Times Higher Education Supplement 23.01.04, p. 10)}

In (7), DU (again, as in texts (1)-(3), (5) and (6), a thetic utterance) asserts the existence of a measure introduced by Imperial College London, the subject-matter of this longer and more complex text. This lead sentence expands the highly condensed title, ${ }^{19}$ and grounds the text as a whole. $\mathrm{DU}^{1}$ is an Elaboration of this, providing further details about what is on offer for student volunteers at that University. The anaphoric relation established between the reduced definite NP subject of $\mathrm{DU}^{1}$ The students and the referent of the indefinite, introductory NP 20 student volunteers in $\mathrm{DU}^{\circ}$ ensures this connection, together with the opening of a new paragraph (a unit of text): the latter is thereby signaled as being primarily about the 20 students in question. The zero subject of $\mathrm{DU}^{2}$ is understood in terms of a third-order entity, retrieving the 'fact' corresponding to the content of $\mathrm{DU}^{1}$. The participial structure of $\mathrm{DU}^{2}$, the presence of the adverb hopefully and the obligatory coreference of the zero subject of the participle with a referent evoked via the clause to which it connects, $\mathrm{DU}^{1}$, suggest a Purpose relation between the two propositions: indeed, one of the connectives so or thereby could be inserted between the two units. The integrated discourse unit $\left[\mathrm{DU}^{1}+\mathrm{DU}^{2}\right]$ relates to the more central unit $\mathrm{DU}^{\circ}$ in terms of an Elaboration relation, in that it provides details as to what the students participating in the scheme will be expected to do, as well as why.

As for $\mathrm{DU}^{3}$, this is another Elaboration of $\mathrm{DU}^{\circ}$, with the reduced definite subject NP The bursaries connecting via anaphora with the referent 'annual $£ 1,500$ bursaries offered by ICL to 20 student volunteers' evoked in $\mathrm{DU}^{\circ}$ (as also, though more generally, in the title). This relation is specified in a parallel way to that of 'the students' in $\mathrm{DU}^{1}$, signaling the opening of a parallel discourse unit via a new textual paragraph dealing with the other main topic entity associated with this text. $\mathrm{DU}^{4}$, a non-restrictive relative clause, is syntactically dependent on the subject of $\mathrm{DU}^{3}$ owing to the presence of the subject relative pronoun which

\footnotetext{
19 Where it is not made clear what the 'volunteers' are actually volunteering for - though the fact that the article appeared in a newspaper devoted to higher education would lead the reader to expect that this would be the factor involved.
} 
- although it is not strictly necessary for this connection to be made: see $\mathrm{DU}^{2}$ in text (5) in this respect, where the relative pronoun and passive auxiliary are ellipsed. Thus it relates to this unit in terms of the relation Elaboration, providing as it does information about the source of the bursaries on offer. $\mathrm{DU}^{5}$ is indicated as being connected with the result of the integration of $\mathrm{DU}^{3}$ with $\mathrm{DU}^{4}$ (minimally) in terms of a Parallel relation, owing to the conjunction and which introduces it. The NP those from less well-off backgrounds has the contextually-expanded interpretation 'those [students eligible for the bursaries on offer] (who are) from less well-off backgrounds' (see also the elliptical demonstrative phrase those present in text (6)).

Finally, $\mathrm{DU}^{6}$ is connected to the integrated unit $\left[\left[\mathrm{DU}^{3}+\mathrm{DU}^{4}\right]+\mathrm{DU}^{5}\right]$ in terms of a Contrast relation, since the adversative conjunction but may coherently be inserted in front of $\mathrm{DU}^{6}$. The contrast is established between the two parallel arguments involved in each proposition (respectively, 'student volunteers from less well-off backgrounds' and 'students already involved in the pupil support scheme'), in terms of a common predicate 'being eligible for' or 'being targeted at': see the definition of Contrast given by Hobbs (1990) reproduced in cell 3 of the third column in Table 2. The discourse structure corresponding to this more complex text is given in Figure 2.

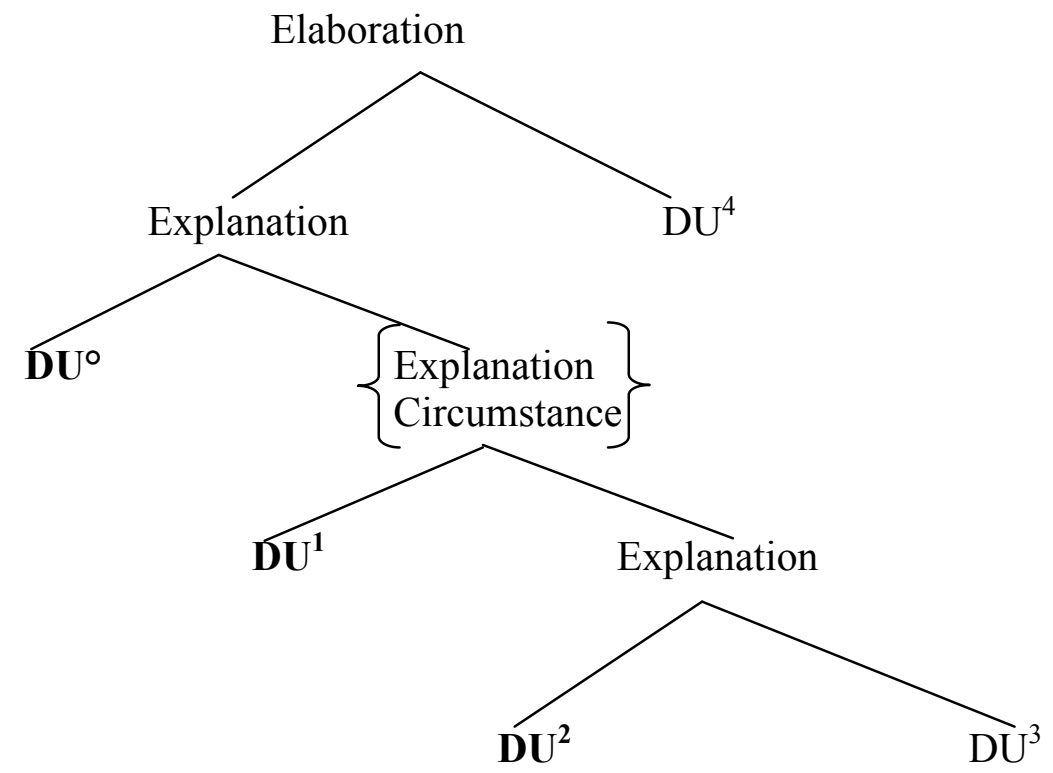

Figure 2: Discourse structure of text (7), after Hobbs (1990, Chapter 5)

This example clearly points up the hierarchical structure of the discourse corresponding to texts, in reflection of the fact that the relations contracted by the discourse acts associated with the successive sentences and clauses within a text do not always exist at the level of pairs of sentences and/or clauses immediately following one another in the linear concatenation of the text (cf. Asher and Lascarides, 2003; Giora, 1985). See in this regard the text/discourse distinction formulated in Table 1.

\section{Conclusion: toward a possible processing scenario}

In the simple 2- or 3-sentence texts presented above, relevant general or specific world knowledge is activated via the title and/or via reading the initial, lead sentence or clause of the text (for example, in (3), the fact that Lima is the capital of Peru). On reading this first clause or sentence, the reader will be setting up several anticipated interpretations of what is to 
come. This processing activity may invoke a particular coherence relation as a provisional integrative framework within which to connect the contents and discourse values of the upcoming unit. This is a function of the reader's hypothesis as to the writer's intention (his/her degree of commitment to the proposition being expressed, keyed by the modal indications present in the clause, including clause mood and the nature of its likely accompanying illocutionary force). For example, on reading the initial sentence of (1) and of (6), there is a strong assumption of the relevance of the relation Claim-Evidence.

On reading the second clause or sentence of the text, the need to update the discourse context already established (often provisionally) via the processing of the first clause or sentence and the title (where there is one) inevitably arises. There are three distinguishable stages in this process of updating. ${ }^{20}$

First, establishing minimal commonalities for the states of affairs evoked - identifying a common location (whether geographical or more abstract - 'cognitive' space) in which to ground the eventualities that occur or exist. For example, in (2), it is 'the aircraft cabin', and in (3), 'Peru'. In texts (1) and (6), the common 'space' is, more abstractly, 'John's know-how world' and 'the UK Conservative party', respectively. (The time of each state of affairs may of course differ - as in (3)). This identity of place, conceived broadly to include 'cognitive space' as in (1) and (6), provides a bedrock for the integration of the two states of affairs evoked. The essential function of title and lead sentence is to ground the discourse to be constructed via processing of the remainder of the article.

The next stage will be to search for evidence to confirm (or otherwise) the prediction, derived from processing the first clause or sentence and the title, of the relevance of a given coherence relation. This involves, first, fleshing out the propositional content of the clause or sentence being processed and deciding on its likely illocution. Cues to this will be the lexical relation potentially obtaining between main predicators in each sentence or clause (or in more general terms, the relation in terms of what is predicated of what in each), as well as tense and Aktionsart relations; also the possible presence of a connective of a particular kind. The testing of the relevance of a given coherence relation initially hypothesized will assign a provisional interpretation to any anaphors present in the second clause or sentence, in part as a function of topic-comment relations with regard to the context unit. This will make it possible to assess whether their likely referents can be the arguments of each predication as specified in the semantic structure of one of the 'Expansion/Resemblance' relations (here, Parallel, Elaboration, Contrast or Claim-Evidence). The anaphoric clause or sentence will select the context discourse unit with which the coherence relation is to be established, in terms of the type of anaphor(s) within it and of what is predicated of its or their referent. ${ }^{21}$

At a second level within this second stage, final confirmation or disconfirmation will be decided as to the applicability in context of the coherence relation initially hypothesized. This will be carried out by processing more deeply various other cues available in the second clause or sentence. It is at this second, confirmatory stage that the complete, expanded interpretation of the anaphor(s) present will be implemented. The possible instantiation of its or their referential value will be effected in terms of that of the matching referent evoked via the connecting unit as a function of the coherence relation involved. See as an illustration, in particular, the way in which the full, final interpretation of the partially elliptical anaphors those present in $\mathrm{DU}^{2}$ in text (6) and those from less well-off backgrounds in $\mathrm{DU}^{5}$ in (7) is achieved. This clinches the applicability of the coherence relation tested in the first part of this

\footnotetext{
20 Whether certain of the components of discourse processing identified here occur sequentially or in parallel is, of course, a matter for psycholinguistic testing. I am indebted to Stavroula-Thaleia Kousta for this important point.

21 See Garrod and Sanford (1999) for psycholinguistic evidence that anaphor resolution in reading may occur in two distinct stages - the first involving partial or superficial processing, the second entailing a fuller integration with the relevant discourse context.
} 
second stage, whereupon the integration will actually take place. This 'confirmatory' stage in processing will see the fleshing out by default of textually inexplicit items (e.g. that the "vital cable' in text (2) is one that is "in or on the aircraft on board which the hamster had been smuggled": cf. Mann \& Thompson's 1986 notion 'relational proposition'). It is here too that a possible second, 'stronger' coherence relation (if compatible with the initial, 'weaker' one) may be invoked. See as examples the relation Occasion strengthened to Cause-Consequence in the second clause of text (2), Elaboration potentially strengthened to Explanation in the second sentence of text (3), and Elaboration to Evidence connecting $\left[\mathrm{DU}^{1}+\mathrm{DU}^{2}\right]$ to $\mathrm{DU}^{\circ}$ in text (6).

The third and final stage involves fitting the composite, integrated unit that is the output of this integration process into the developing discourse model, which is located in working memory (see Baddeley, 1987; Cowan, 1997) prior to being lodged in long-term memory for retention when complete.

The resolution of the anaphors occurs, then, in two distinguishable stages, interleaved with the establishment of given coherence relations: initially, and provisionally, at stage 2(i), where the applicability of the coherence relation anticipated as part of the construction of the discourse context is tested for. Here, they are given provisional assignments in terms of the relevant argument positions within the coherence relation's semantic structure (this is broadly equivalent to Garrod and Sanford's 1999 notion 'bonding'). And secondly, and finally, at stage 2(ii), where the coherence relation initially invoked is finally decided upon and implemented (or is overlaid by a pragmatically 'stronger' one). The anaphors concerned will now receive a full, expanded interpretation. It is here that the anaphor's resolution may be seen as the sine qua non of the implementation of a given coherence relation. The initial, provisional, stage in anaphor interpretation would correspond to Hobbs's (1979) original hypothesis, whereby it is the choice of a given coherence relation which ultimately determines the reference of anaphors in the second discourse unit involved in the relation.

Inter-sentential anaphors, then, far from being merely 'resolved as a by-product' of the implementation of a given coherence relation holding between two discourse units, are an essential pillar supporting the overlay of that relation in fleshing out and integrating their discourse values. Just as a 'weaker' semantically- or textually-based coherence relation (e.g. Elaboration or Ground-Figure) will often be invoked by default at the initial stages in the processing of a multi-clausal text, with a 'stronger' pragmatically-oriented relation possibly overlaid upon it at stage 2(ii), so the processing of anaphors in subsequent clauses or sentences goes through two distinguishable processing stages — 'bleeding' as well as buttressing the implementation of that or those relation(s).

\section{*Acknowedgement}

This article is a substantially revised and extended version of a paper first presented at the Workshop Unité(s) $d u$ Texte, organized by the CRISCO research unit of the University of Caen, France, which took place there on 6 December 2002. The paper was entitled 'Types de relations de discours entre énoncés: interactions avec l'anaphore transphrastique', and was based largely on French textual examples. A second (further revised) presentation took place at the Department of Modern Languages of the Norwegian University of Science and Technology, Dragvoll, Trondheim, on 31 May, 2005. A third was given at a one-day Workshop at the University of Toulouse II on 29 June 2007, presenting the results of a 3-year research project (2003-2006) under the aegis of the Institut de Linguistique Française, entitled Relations de cohérence et fonctionnement des anaphores. The project was jointly carried out by research units from the Universities of Toulouse II and Strasbourg II under my direction.

I would like to thank Michel Charolles, Ted Sanders, Josette Rebeyrolle, Christopher Butler, StavroulaThaleia Kousta, Thorstein Fretheim, Georges Kleiber, as well as Nigel Love and an anonymous Language Sciences referee for commenting on various preliminary versions of this article. All responsibility for the opinions expressed here and for any errors which may persist is mine alone. 


\section{References}

Akman, V., Bazzanella, C. (Eds.) 2003. The Complexity of Context. Special issue of Journal of Pragmatics 35 (3).

Arnold, J.E. 2001. The Effect of Thematic Roles on Pronoun Use and Frequency of Reference Continuation. Discourse Processes 31 (2), 137-162.

Asher, N., Lascarides, A. 1996. Lexical Disambiguation in a Discourse Context. In: Pustejovsky, J., Boguraev, B. (Eds.), Lexical Semantics: The Problem of Polysemy. Clarendon Press, Oxford, pp. 69-108.

Asher, N., Lascarides, A. 2003. Logics of Conversation. Cambridge University Press, Cambridge.

Auer, P. 1992. Introduction: John Gumperz' Approach to Contextualization. In: Auer, P., di Luzio, A. (Eds.) The Contextualization of Language. John Benjamins, Amsterdam/Philadelphia, pp. 1-37.

Baddeley, A. 1987. Working Memory. Clarendon Press, Oxford (Oxford University Press).

Bianchi, C. 2004. Semantics and Pragmatics: The Distinction Reloaded. In: Bianchi, C. (Ed.), The Semantics/Pragmatics Distinction. Leland Stanford Junior University, CSLI Publications, pp. 1-11.

Connolly, J. H. 2007. Context in Functional Discourse Grammar. Alfa. Revista de Linguística $51(2), 11-33$.

Cornelis, L. 2003. Ajax is the Agent. Subject versus Passive Agent as an Indicator of the Journalist's Perspective in Soccer Reports. In: Ensink, T., Sauer, C. (Eds.), Framing and Perspectivizing in Discourse. John Benjamins, Amsterdam/Philadelphia, pp. 171189.

Cornish, F. 2008. How indexicals function in texts: Discourse, text, and one neo-Gricean account of indexical reference. Journal of Pragmatics 40, 997-1018.

Cowan, N. 1997. Attention and Memory. An Integrated Framework. Clarendon Press, Oxford (Oxford University Press).

Crawley, R.A., Stevenson, R.J., Kleinman, D. 1990. The Use of Heuristic Strategies in the Interpretation of Pronouns. Journal of Psycholinguistic Research 19 (4), 245-264.

Den Uyl, M. 1983. A Cognitive Perspective on Text Coherence. In: Ehlich, K., van Riemsdijk, H. (Eds.), Connectedness in Sentence, Discourse and Text. Katholieke Hogeschool, Tilburg, pp. 259-283.

Dowty, D. R. 1986. The Effects of Aspectual Class on the Temporal Structure of Discourse: Semantics or Pragmatics? Linguistics and Philosophy 9, 37-61.

Fabricius-Hansen, C., Behrens B. 2001. Elaboration and Related Discourse Relations Viewed from an Interlingual Perspective. SPRIK report of the project Languages in Contrast, University of Oslo. (Available at http://www.hf.uio.no/german/sprik).

Fetzer, A. 2004. Recontextualizing Context. John Benjamins, Amsterdam/Philadelphia.

Garrod, S., Sanford, A. 1999. Ch. 1: Incrementality in Discourse Understanding. In: van Oostendorp, H., Goldman, S.R. (Eds.), The Construction of Mental Representations during Reading. Lawrence Erlbaum Associates, Mahwah, N.J., pp. 3-27.

Gennari, S.P. 2004. Temporal References and Temporal Relations in Sentence Comprehension. Journal of Experimental Psychology: Learning, Memory and Cognition 30 (4), 877-890.

Giora, R. 1985. Notes towards a Theory of Text Coherence. Poetics Today 6 (4), 699-715.

Givón, T. 2005. Context as Other Minds. The Pragmatics of Sociality, Cognition and Communication. John Benjamins, Amsterdam/Philadelphia. 
Gumperz, J. J. 1992a. Ch. 8: Contextualization and Understanding. In: Duranti, A., Goodwin, C. (Eds.), Rethinking Context. Language as an Interactive Phenomenon. Cambridge University Press, Cambridge, pp. 229-252.

Gumperz, J. J. 1992b. Contextualization Revisited. In: Auer, P., di Luzio, A. (Eds.) The Contextualization of Language. John Benjamins, Amsterdam/Philadelphia, pp. 39-53.

Hobbs, J. R. 1979. Coherence and Coreference. Cognitive Science 3, 67-90.

Hobbs, J.R. 1990. Ch. 5: The Coherence and Structure of Discourse. In: Literature and Cognition. Leland Stanford Junior University, Calif., CSLI Lecture Notes 21, pp. 83114.

Jarvella, R.J. (1979). Immediate memory and discourse processing. In: Bower, G.B. (Ed.), The Psychology of Learning and Motivation Vol. 13. Academic Press, New York.

Jaszczolt, K.M. 2005. Default Semantics. Oxford University Press, Oxford.

Kehler, A. 2002. Coherence, Reference and the Theory of Grammar. CSLI Publications, Stanford University.

Kehler, A. 2004. Ch.11: Discourse Coherence. In: Horn, L.R., Ward, G. (Eds.), The Handbook of Pragmatics. Blackwell Publishing, Oxford, pp. 241-265.

Knott, A., Sanders, T. 1998. The Classification of Coherence Relations and their Linguistic Markers: An Exploration of Two Languages. Journal of Pragmatics 30, 135-175.

Madden, C.J., Zwaan, R.A. 2003. How does Verb Aspect Constrain Event Representations? Memory and Cognition 31 (5), 663-672.

Mann, W.C., Thompson, S.A. 1986. Relational Propositions in Discourse. Discourse Processes 9, 57-90.

Mann, W. C., Thompson, S. A. 1988. Rhetorical Structure Theory: Toward a Functional Theory of Text Organization. Text 8 (3), 243-281.

Mann, W.C., Mathiessen, C.M.I.M., Thompson, S.A. 1992. Rhetorical Structure Theory and Text Analysis. In: Mann, W.C., Thompson, S.A. (Eds.), Discourse Description: Diverse Linguistic Analyses of a Fund-Raising Text. John Benjamins, Amsterdam, pp. 39-78.

Marcu, D. 2000. The Rhetorical Parsing of Unrestricted Texts: A Surface-Based Approach. Computational Linguistics 26 (3), 395-448.

Murphy, M. L. 2003. Semantic Relations and the Lexicon. Cambridge, Cambridge University Press.

Parisi, D., Castelfranchi, C. 1977. The Discourse as a Hierarchy of Goals. Signs of Change 1 (2), 31-67.

Peleg, O., Giora, R., Fein, O. 2004. Ch. 8: Contextual Strength: The Whens and Hows of Context Effects. In: Noveck, I.A., Sperber, D. (Eds.), Experimental Pragmatics. Palgrave MacMillan, Basingstoke/New York, pp. 172-186.

Reinhart, T. 1984. Principles of Gestalt Perception in the Temporal Organization of Narrative Texts. Linguistics 22, 779-809.

Rossari, C. 2000. Connecteurs et Relations de Discours: Des Liens entre Cognition et Signification. Presses Universitaires de Nancy, Nancy.

Rothstein, S. 2004. Structuring Events. A Study in the Semantics of Lexical Aspect. Blackwell, Malden, USA/Oxford, UK/Carlton, Australia.

Roulet, E. 2002. Ch. 7: De la Nécessité de Distinguer des Relations de Discours Sémantiques, Textuelles et Praxéologiques. In: Andersen, H. L., Nølke, H. (Eds.), Macro-Syntaxe et Macro-Sémantique. Actes du Colloque d'Arhus, 17-19 mai 2001. Peter Lang, Bern, pp. 141-165.

Ruhl, C. 1974. Semantic Anaphora. Papers in Linguistics 7 (1-2), 205-238. 
Sanders, T.J.M. 1997. Semantic and Pragmatic Sources of Coherence: On the Categorization of Coherence Relations in Context. Discourse Processes 24, 119-147.

Sanders, T.J.M., Noordman, L.G.M. 2000. The Role of Coherence Relations and their Linguistic Markers in Text Processing. Discourse Processes 29 (1), 37-60.

Sanders, T.J.M., Spooren, W.P.M., Noordman, L.G.M. 1993. Coherence Relations in a Cognitive Theory of Discourse Representation. Cognitive Linguistics 4, 93-133.

Schauer, H., Hahn, U. 2001. Anaphoric Cues for Coherence Relations. In: Angelova et al., G. (Eds.), Proceedings of the International Euroconference 'Recent Advances in Natural Language Processing' - RANLP 2001, Tzigor Chark, Bulgaria, 5-7 September 2001. Shoumen, Incoma, pp. 228-234.

Schwarz, M. 2001. Establishing Coherence in Text. Conceptual Continuity and Text-World Models. Logos and Language 11 (1), 15-23.

Smith, C. S. 2003. Modes of Discourse. The Local Structure of Texts. Cambridge University Press, Cambridge.

Spooren, W. 1997. The Processing of Underspecified Coherence Relations. Discourse Processes 24, 149-168.

Unger, C. 2006. Genre, Relevance and Global Coherence. The Pragmatics of Discourse Type. Palgrave MacMillan, Basingstoke and New York.

Webber, B., Joshi, A., Stone, M., Knott, A. 2003. Anaphora and Discourse Structure. Computational Linguistics 29 (4), 545-587.

Widdowson, H.G. 2004. Text, Context, Pretext. Critical Issues in Discourse Analysis. Blackwell, Oxford.

Wolf, F., Gibson, E., Desmet, T. 2004. Discourse Coherence and Pronoun Resolution. Language \& Cognitive Processes 19, 665-675.

Yang, C.L., Gordon, P.C., Hendrick, R., Wu, J.T., Chou, T.L. 2001. The Processing of Coreference for Reduced Expressions in Discourse Integration. Journal of Psycholinguistic Research 30, 21-35. 